\section{Charpentier (1891) on the size-weight illusion}

\author{
DAVID J. MURRAY, ROBERT R. ELLIS, \\ and CHRISTINA A. BANDOMIR \\ Queen's University, Kingston, Ontario, Canada \\ and \\ HELEN E. ROSS \\ University of Stirling, Stirling, Scotland
}

This paper offers background for an English translation of an article originally published in 1891 by Augustin Charpentier (1852-1916), as well as a summary of it. The article is frequently described as providing the first experimental evidence for the size-weight illusion. A comparison of experiments on the judged heaviness of lifted weights carried out by Weber (1834) and by Charpentier (1891) supports the view that Charpentier's work deserves priority; review of other experimental studies on the size-weight illusion in the 1890 s suggests that the idea that the illusion depended on "disappointed expectations," especially with respect to speed of lift, became dominant almost immediately following the publication of Charpentier's paper. The fate of this and other ideas, including "motor energy," in 20th-century research on the illusion is briefly described.

It is often stated (e.g., Jones, 1986, p. 36) that the first demonstration of the size-weight illusion is that in Charpentier (1891); below we shall show that this statement is historically acceptable, insofar as writings on weight perception prior to 1891 provided no experimental demonstrations of the illusion. Because of its historical importance, we have prepared a translation of Charpentier's paper, which originally appeared in French in a physiological journal. This translation can be accessed on the World-Wide Web at the address indicated in the acknowledgements note.

The present paper presents a brief historical introduction to Charpentier's paper, a summary of it, and an account of the immediate reactions to it; we also highlight the relevance of this early research to recent work.

This research was supported by Research Grant 410-96-0501 awarded to the first author by the Social Sciences and Humanities Research Council of Canada. We are most grateful to Dr. Serge Nicolas of the Université René Descartes (Paris V) for obtaining for us a copy of Dufour's obituary notice concerning Charpentier. We are also grateful to reviewer Eric L. Amazeen for his helpful suggestions for improvements to the first draft. Reprint requests should be addressed to D. J. Murray, Department of Psychology, Queen's University, Kingston, ON, K7L 3N6 Canada (e-mail: murrayd@pavlov.psyc.queensu.ca). A copy of the English translation of Charpentier's 1891 article will be sent with the reprint. Otherwise the translation can be accessed on the World-Wide Web at the following address: http://pavlov.psyc.queensu. ca/faculty/murray/charp.html

\section{Historical Introduction}

One of our aims here is to provide more evidence than has previously been available in English that Charpentier indeed deserves priority in the matter of the size-weight illusion. We therefore examined the English translations (Ross \& Murray, 1996) of the two books on the touch sense written in 1834 and 1846 by Ernst Heinrich Weber (1795-1878). Weber's main findings about weight perception are as follows: The parts of the body vary in their sensitivity to, and their ability to discriminate between, weights applied to their surfaces; the left side of the body is more sensitive than the right in this regard; weight discrimination is finer when the weight is picked up by the fingers than when it is placed on the palm. Picking a weight up with the fingers adds muscular sensations to pressure sensations. However, Weber does not explicitly mention the size-weight illusion, although he does state that objects of differing shape and density differ in apparent heaviness, since pressure per unit skin area is an important variable (Ross \& Murray, 1996, p. 63). However, elsewhere ( p. 118) he suggests that total skin area counteracts this effect.

Weber also makes no mention of the effects of order and contrast, which were topics of great interest to subsequent authors. The order effect was known as the "time error" (after Fechner's Zeitfehler) or the "time-order error" (see Hellström, 1985, and Poulton, 1989), in which the second of two equal weights usually feels heavier than the first. Related to it was the "space error" (Fechner's Raumfehler), in which a given weight usually feels heavier in the left hand than in the right. Fechner (1860a) suggested that the presentation orders should be counterbalanced when measuring the differential threshold. Of more importance for the size-weight illusion was the contrast effect known as the Einstellung ("set") effect. If after having repeatedly lifted two weights, $X$ and $Y$, with $X$ much heavier than $Y$, we then lift two weights, $Z$ and $Y$, with $Z$ only slightly heavier than $\mathrm{Y}, \mathrm{Z}$ is usually judged (mistakenly) to be lighter than $Y$.

Fechner's carried out his main weight experiments between 1856 and 1859 , and he reported on them in his $E l$ ements of Psychophysics (Vol. 1, Fechner, 1860a). The experiments concerned the time and space errors, but not the size-weight illusion. Fechner mentioned the Einstellung effect in a separate paper on contrast in vision (Fechner, 1860b, p. 76), where he briefly discussed contrast effects in other senses. This is the section on heaviness perception:

It is easy to create experiences [similar to those of vision] in the realms of other kinds of sensations. If, in the course of my experiments on sensitivity to differences in heaviness [Gewicht], I carry out a series of trials with heavy weights and then suddenly go over immediately to very light weights, or lift an empty vessel that has no load in it, I have the impression, not merely that there is no load to be felt, but that 
the lifted vessel itself seems to me to have a negative heaviness, so to speak.

This sensation of lightness instead of heaviness is always something positive in the sense that it cannot be confused with an absence or unawareness of sensation. On the other hand, the difference between this sensation and those associated with the previous trials is something negative and the sensation of this difference determines, in this case, the conscious experience [das Bewusstsein].

This comment of Fechner's may be the first report of the Einstellung effect for lifted weights. Müller and Schumann (1889) demonstrated the same effect when the weights were lifted simultaneously or sequentially in the two hands. They argued that the effect was not due to a space error, since the direction of judgments went counter to the usual handedness effect. They also noted that the affected comparison weight was often lifted high in the air. They argued that the main cue used to judge weight was the speed with which we lift the object: the faster the lift, the lighter it feels. The typical action of bouncing the hand or "hefting" (French, soupeser) shows that such motions aid weight perception. However, we also use subsidiary cues, including sensations of pressure and muscle tension. When these sensations are absent (as in certain pathological conditions), the patients report that most weights feel light. Müller and Schumann also discussed the role of imagery of one's own movements [Bewegungsbild], and argued that the Einstellung effect arises because long experience with a heavy weight in one hand leads the subject to form an image of a slow lift. The subject, who is then surprised to find his arm rising quickly, judges the weight to be light.

Müller and Schumann (1889) dismissed other explanations, including the theory that subjects pay attention to "sensations of innervation." This term refers to sensations arising in the brain when a subject "wills" a movement. Because the brain has no sensory endings, however, the very idea of such sensations is neurologically suspect; moreover, as William James (1890/1950, Vol. II, pp. 499522) put it, "there is no introspective evidence of the feeling of innervation," although, as he also stressed, there could be "mental cues" such as feelings of effort, or mental images, prior to the execution of a willed action. The early literature on whether sensations of innervation exist in addition to these other feelings or "mental cues" has been reviewed by Boring (1942, pp. 527-529), Ross and Bischof (1981), and Scheerer (1987). The term had practically disappeared by about 1900 , though related concepts continued to be discussed under other names, such as "corollary discharge" (Sperry, 1950), "efference copy" (Holst, 1954), "monitoring of command signals" (Gregory, 1958), and other variants.

Again, in all of this long article, there was no reference to the size-weight illusion. The first study to report $e x-$ perimental data on the illusion does therefore appear to be that of Charpentier (1891), who refers to no prior literature on the subject. This need not be taken, however, to imply that the illusion was unknown prior to Charpentier's work; in fact James (1890/1950) discusses in detail how our perception of heaviness depends on our prior expectations of how heavy an object should feel, given our prior experience of it (Vol. II, pp. 501-503). But he does not use the word "illusion" in this context, only the word "surprise" when an expected sensation of heaviness does not materialize on one's lifting the object; and he provides no deliberately obtained experimental evidence.

\section{Charpentier's (1891) Article}

Augustin Charpentier was born on June 14, 1852, in the small French town of Argenton-sur-Creuse in the centrally located département of Indre. He studied medicine at the nearest academic center, Limoges, and defended his doctoral thesis in Paris in 1877. He decided at this time to specialize in ophthalmology, and his first academic appointment was with the faculty of medicine at the University of Nancy in eastern France. At first, he was mainly concerned with clinical practice, but he found himself drawn to research, particularly in physiological optics. During his long career at Nancy, he published a total of 289 papers, the quality of which was acknowledged by his receiving several prizes from the Academie des Sciences and being made a Chevalier of the Legion of Honor in 1906. He died on August 4, 1916, in the town in which he had been born. More details about his discoveries concerning visual science are given in the useful obituary by Dufour (1916). The following is a summary of the contents of his 1891 article.

The article was divided into 10 sections. Charpentier opened section I by noting that practical difficulties often prevent experimenters from demonstrating that Weber's law applies to weight discrimination. He stated that he would try to throw some light on these difficulties, and thereby on the physiological processes underlying weight perception.

An object's weight can be judged through pressure sensations alone, but sensations from muscular contractions add precision. An additional variable is the amount of "motor energy" (l'énergie motrice) available to us, as is shown by the fact that "a given weight will appear heavier to a child, an old man, or a sick or tired man than it will to a man in good health" (section II, p. 124). Thus a weight feels lighter the greater the number and thickness of the muscles lifting it.

As proof, a chair feels lighter if lifted with two hands rather than one. But the arrangement of the hands is also important. If they are placed a certain distance apart on the upper cross-bar of the chair, the chair will feel lighter than if one hand is placed at the center and the other is cupped on top of it. This suggests that sensations of pressure are in part determined by the area of skin surface in contact with the weight.

To examine this idea, Charpentier placed two spheres of different sizes but each weighing $266 \mathrm{~g}$ onto subjects' supine palms, and asked them to heft the spheres. The 
small sphere was judged to be heavier than the large. But if the subjects lifted each sphere with a single finger inserted into a small hook, the two spheres were judged to be equally heavy. Charpentier concluded that "the less the pressure per unit of surface area, the lower the corresponding sensation of heaviness" (p. 128).

We should note that this experiment was carried out to demonstrate the influence of the area of skin contact. Surprisingly, Charpentier did not indicate here (section IV) whether or not the subject was looking at the spheres; but Flournoy $(1894$, p. 207, n.) contended that Charpentier's subjects may have had their eyes closed. If so, the experiment was not intended as a demonstration of the visual size-weight illusion, which would be described later in section $\mathrm{X}$.

Sections V-IX are devoted to the influence of "motor energy." Several experiments show that a weight lifted with one hand alone feels heavier than when lifted at the same time as another weight in the other hand or lifted with some other part of the body. Charpentier concluded that apparent weight depends not only on the skin contact area but also on the total amount of exertion expended by the whole body. This amount of exertion is also reflected in feelings of effort or tension, and the brain records such feelings. Feelings related to the muscle activity of any one body part have subjective intensities that are proportional to the totality of the feelings of exertion recorded while other body parts are moved at the same time.

In section $X$, Charpentier added a final source of influence on apparent weight--namely, "accompanying mental ideas." For example, when he repeated the experiment in which subjects used the hook handles to lift two equally heavy but different-looking spheres, but now kept their eyes open, the subjects no longer judged the two spheres to be equally heavy (as they had when they had carried out the task with eyes closed). The smaller sphere was now judged to be heavier than the larger sphere. This is the only mention of the size-weight illusion in Charpentier's paper.

Charpentier claimed that the illusion could be explained if the subject had "preliminary ideas" about heaviness based on previous experience. He went on to ask: "But is not such an idea itself a motor phenomenon, a cerebral effort, positive or negative as the case may be?" (Charpentier, 1891, p. 135). If these "preliminary ideas" were simply subcategories of "feelings of mental effort," the perception of heaviness would depend on only two kinds of feelings: those of pressure on the skin and those of cerebral effort.

\section{The Immediate Consequences of Charpentier's Article}

The first reaction to Charpentier's article was that of Flournoy (1894), who wrote an article in French in which he argued that the size-weight illusion could be explained by falsified expectations and by the manner of lifting. (A summary of the life and work of Théodore Flournoy
[1854-1920] has recently been provided by Nicolas [1998].)

Flournoy (1894) tested 50 subjects, using 10 objects all weighing $112 \mathrm{~g}$ but of different sizes and shapes. The smaller the object looked, the greater its apparent weight. However, the illusion vanished if subjects closed their eyes while lifting the weights by wire handles. Flournoy suggested that subjects prejudged the weight of an object by its visual size and then set themselves to lift it with a certain force-an inappropriate force in the case of illusions. He quoted with approval the idea of Müller and Schumann (1889) that speed of lift was a key variable in weight perception. Flournoy believed that the illusion depended on the subject's forming an image (perhaps with visual as well as motor components) of how heavy he thought a weight would be.

Flournoy stated that Charpentier preferred an explanation of the size-weight illusion in terms of sensations of innervation. However, this claim can be questioned. The words sensations of innervation are completely absent from Charpentier's text. He speaks of "a notion of the degree of effort set into operation by the brain when we command that the movement be executed" (section VI). He also says in section IX: "[the brain] sends a signal [donne une impulsion] to the muscle to set the latter in motion and records the feeling associated with this signal [ressent cette impulsion]." There is a translation problem here as to whether the word ressent means "senses" or "records," but the latter is more likely. More importantly, Charpentier's remarks about "feelings" in the brain do not refer to the size--weight illusion, but to lifting two weights at once. When he discusses the sizeweight illusion (section $\mathrm{X}$ ) he states that it depends on an "idea," and that this "idea" itself consists of a cerebral effort; he does not specify in detail how this could explain the illusion. Nevertheless, it is probably fair to say that Charpentier intended an explanation in terms of sensations of innervation. A more specific explanation involving incomplete sensations of innervation was provided by Martin and Müller (1899): One learns to exert a larger force when lifting larger objects, but part of that force is unwitting or unsensed, so that a fast lift is attributed to a light object rather than to a strong lift (summarized by Hershberger \& Misceo, 1983).

Meanwhile, at the Psychological Laboratory founded at Yale by G. T. Ladd (1842-1921) in 1881 and handed over by Ladd to E. W. Scripture (1864-1945) in 1892, at least three experimentalists-Scripture himself, J. A. Gilbert (1867-?), and C. E. Seashore (1866-1949)-investigated the illusion. At the same time, at Clark University, F. B. Dresslar (1858-1930) was studying the illusion in school children. The three main papers reporting data were those of Gilbert (1894), Dresslar (1894), and Seashore (1895); but the work was begun in 1893 and may have been started without knowledge of Flournoy's experiments. Scripture (1897) stated that Gilbert's "were the first measurements made on the size-weight illusion" 
(p. 227); but his student Seashore (1895, p. 1) explicitly referred to the studies of Charpentier and of Flournoy.

We shall summarize this American research only briefly. Gilbert (1894) used the illusion to determine whether children's "suggestibility" changed with age; he found that the illusion increased over ages 6-9 and then decreased up to age 17 , with girls being more susceptible than boys. Seashore (1895) showed that the illusion could be reduced by giving instructions about its nature and could be increased by providing more visual information about the objects. Seashore also measured the illusion when the object was gripped as compared with when it was placed on the outstretched palm. Later, Scripture (1897) suggested that the size of the illusion in Seashore's experiments could be measured by a formula involving volume and true weight. Dresslar (1894) worked independently on the illusion and noted that neither Weber nor Fechner had studied it, and that he had not come across Charpentier's work till later. He found the usual illusion present in children, and also found that objects of compact shape felt heavier than those of sprawling appearance.

By 1895 there was an extensive collection of data on the size-weight illusion, much of it carried out in Scripture's laboratory, where the theoretical focus was not on the illusion as an undesirable artifact, but as a category of mental mistake (along with hallucinations and other phenomena) resulting from disappointed expectations. Meanwhile, work continued in Europe on the idea that these disappointed expectations were specifically caused by the inappropriate speed of lifting: Claparède (1902) showed that the illusion was correlated with faster lifts for larger objects, and he emphasized the neurophysiological rather than the mental components of the illusion. The debate has continued through the 20th century.

\section{The Continuing Relevance of Charpentier's Ideas}

Many psychophysicists have restricted themselves to establishing mathematical relationships between apparent weight, physical weight, density, and other variables (see Poulton, 1989). Charpentier, however, as a physiologist, was concerned with explaining weight perception in neurophysiological terms, such as the pressure per unit area on the skin and the relative amount of motor energy required to lift the object. Nevertheless, he thought that the visual size-weight illusion required an additional psychological component-an "accompanying mental idea" or "feeling of mental effort." The debate continues between those who would explain the illusion at a peripheral level, and those who emphasize expectations. A modern example of a peripheral explanation is that of Amazeen and Turvey (1996), who claim that the illusion is caused by differences in rotational inertia of objects of different density, and that no inference is involved.

Of Charpentier's ideas, that of "pressure per unit area of skin" was relatively uncontroversial and did not generate many experiments. Those of "motor energy" and "accompanying mental idea" remained controversial and hard to disentangle, as did those of others concerning "disappointed expectations" and the speed of lifting. We shall concentrate on these controversial themes.

Motor energy. There are some difficulties in unraveling the concepts of weight, force, and mass. Strictly speaking, weight is a force; nevertheless, the term is popularly used to refer to the mass of an object. The subjective heaviness of an object is determined partly by force and partly by other cues to mass. Charpentier was aware of this when stating that motor energy was only one of the cues used. Psychophysicists have continued to study the scaling of force (or perhaps weight) estimates, and the resulting functions vary with the scaling procedure (see reviews by Jones, 1986; Poulton, 1989). Charpentier's idea that a person's strength or maximum energy affects the perception of heaviness continues to be confirmed. The topic requires the measurement of subjective differences between strong and weak individuals, or of differences within the same subject under different conditions. Interindividual comparisons can be made through scaling procedures such as those of Borg (1962); Teghtsoonian, Teghtsoonian, and Karlsson (1981); and Borg, Olsson, Borg, and Neely (1996). Intraindividual comparisons can be made by contralateral limb matching techniques, in which the forces exerted by a group of muscles in the reference limb are matched in subjective magnitude by the other limb. This technique allows measurement of the effects of muscular fatigue, partial curarization, or neurological disorders. In general, muscular weakness leads to an increase in the perceived heaviness of objects, or in the perceived force exerted; but the findings vary with different test methods and instructions (see review by Jones, 1986).

The effects of other simultaneous muscular activities are still being investigated. For example, Kilbreath and Gandevia (1991) found that a given weight felt heavier if another weight (equally heavy or heavier) was lifted simultaneously by another finger of the same hand, but a simultaneous weight on the ankle had no effect. These findings differ from Charpentier's claim that additional weights make the reference weight feel lighter.

Charpentier failed to spell out how "preliminary ideas" could explain the size-weight illusion: If these ideas were simply added to feelings of motor effort, a large weight should feel heavier than a small weight, instead of lighter. An explanation in terms of contrast was required.

Speed of lifting and disappointed expectations. Some version of the Einstellung effect is the most common explanation for the illusion. The illusion can occur whether the object is judged statically (by pressure alone) or whether it is lifted, so it would be sufficient to say that contrast with the expected weight, or with the physiological adaptation level (Furth, 1960), modifies apparent heaviness. However, many authors have given a specific role to lifting movements. Charpentier stated that a muscular sensation when one is lifting a weight is composed of two elements: the resulting movement, and a record of 
the effort to command the movement. Others have argued that at least one of these elements must be incorrectly registered for a misperception to occur (e.g., Hershberger \& Misceo, 1983; Ross, Schwartz, \& Emmerson, 1987). The role of efferent and afferent sources of weight and force information is reviewed by Jones $(1986,1996)$.

Much current work concerns grip force and load force (see review by Wing, 1996). These forces rise together and are set by the subject's expectations on the basis of previous trials and the appearance of the grip surface texture. There is thus no doubt that motor set affects the manner in which an object is lifted; but whether the inappropriate lift is a cause or a side effect of an erroneous weight judgment is much less clear.

\section{REFERENCES}

Amazeen, E. L.. \& Turvey. M. T. (1996). Weight perception and the haptic size- weight illusion are functions of the inertia tensor. Journal of Experimental Psychology Human Perception \& Performance, 22, 213-232.

BORG, G. (1962). Physical performance and perceived exertion. In Studia Psychologica et Paedogogica-Series Altera. Investigationes XI (pp. 1-64). Lund: Gleerup.

Borg, G., Olsson, M. J , Borg, E., \& Neely, G. (1996). LiMELevel-anchored intersubjective ME. In S. C. Masin (Ed.), Fechner Dav 96 (pp. 215-220). Padua: University of Padua, International Socrety for Psychophysics.

Boring, E. G. (1942). Sensation and perception in the history of experimental psychology. New York: Appleton-Century-Crofts.

Charpentier, A. (1891). Analyse expérimentale: De quelques éléments de la sensation de poids. [Experimental analysis: On some of the elements of sensations of weight]. Archives de Physiologie Normale et Pathologique, 3, 122-135.

ClaparèDE, E. (1902). Expériences sur la vitesse de soulèvement des poids de volumes différents. [Experiments on the speed of liftıng of weights of different volume]. Archives de Psychologie, 1, 69-94.

Dresst.AR, F. B. (1894). Studies in the psychology of touch. American Journal of Psychology, 6, 313-368.

Dufour. M (1916). Augustin Charpentier (1852-1916). Annales D'Oculistique, 43, 505-519.

FeCHNER, G. T. (1860a). Elemente der Psychophysik (2 vols.). Leipzig: Brettkopf \& Härtel. [Reprinted (1964): Amsterdam: E. J. Bonset. Vol. 1 only has been translated into English by H. Adler (1966) as Elements of psvchophysics. New York: Holt, Rinehart \& Winston.]

FeCHNER, G. T (1860b) Über die Contrastempfindung. [On sensations of contrast]. Berichte über die Verhandlungen der königlichsächsischen Gesellschafi der Wissenschaften zu Leipzig, Mathematischphysische Classe, 12,71-145.

FLournoy, T. (1894). De l'influence de la perception visuelle des corps sur leur poids apparent. [On the influence of the visual perception of bodies on their apparent heaviness]. L'Année Psychologique, 1, 198-208.

FurTh, H. G. (1960). The effect of the size-weight illusion on adaptation level. Journal of Experimental Psychology, 60, 150-154.

GILBERT, J. A. (1894). Researches on the mental and physical development of school-children. Studies from the Yale Psychological Laboratorv, 2, 40-100.

GREGORY, R. L. (1958). Eye movements and the stability of the visual world. Nature, 182, 1214-1216.
Hell.ström, A. (1985). The time-order error and its relatives: Mirrors of cognitive processes in comparing. Psychological Bulletin, 97, 3561

Hershberger, W., \& Misceo, G. (1983). A conditioned weight illusion: Reafference learning without a correlation store. Perception \& Psychophysics, 33, 391-398.

Holst, E. von (1954). Relation between the central nervous system and the peripheral organs. British Journal of Animal Behaviour, 2 , 89-94.

JAMES, W. (1890). Principles of psychology (2 vols.). New York: Holt. [Reprinted (1950), New York: Dover.]

JoNES, L. A. (1986). Perception of force and weight: Theory and research. Psychological Bulletin, 100, 29-42.

JONES, L. [A.] (1996). Proprioception and its contribution to manual dexterity. In A. M. Wing, P. Haggard, \& J. R. Flanagan (Eds.), Hand and brain: The neurophysiology and psychology of hand movements (pp. 349-362). London: Academic Press.

Kilbreath, S. L., \& Gandevia, S. C. (1991). Independent digit control: Failure to partition perceived heaviness of weights lifted by digits of the human hand. Journal of Physiology, 472, 537-556.

Martin, L., \& Müller, G. E. (1899). Zur Analyse der Unterschiedsempfindlichkeit [Toward an analysis of sensitivity to differences]. Leipzig: Barth.

MüLler, G. E., \& Schumann, F. (1889). Über die psychologischen Grundlagen der Vergleichung gehobener Gewichte [On the psychological foundations of the comparison of lifted weights]. Archiv für die gesammte Physiologie des Menschen und der Tiere, 45, 37-112.

Nicolas, S. (1998). Théodore Flournoy (1854-1920) and experimental psychology: Historical note. American Journal of Psychology, 111, 279-294.

Poulton, E. C. (1989). Bias in quantifying judgments. Hove, U.K.: Lawrence Erlbaum.

Ross, H. E., \& Bischof, K. (1981). Wundt's views on sensations of innervation: A reevaluation. Perception, 10, 319-329.

Ross, H. E., \& Murray, D. J. (1996). E. $H$ Weber on the tactile senses (2nd ed.) Hove, U.K.: Taylor \& Francis, Erlbaum.

Ross, H. E., SchWARTZ, E., \& EMmERSON, P. (1987). The nature of sensorimotor adaptation to altered $\mathrm{G}$ levels: Evidence from mass discrimination. Aviation. Space, \& Environmental Medicine, 58 (9, Suppl.), A148-A152.

SCHEERER, E. (1987). Muscle sense and innervation feelings: A chapter in the history of perception and action. In H. Heuer \& A. F. Sanders (Eds.), Perspectives on perception and action (pp. 171-194). Hillsdale, NJ: Erlbaum.

SCripture, E. W. (1897). The law of size-weight suggestion. Science, $5,227$.

SEASHORE, C. E. (1895). Measurements of illusions and hallucinations in normal life. Studies From the Yale Psychological Laboratory, $\mathbf{3}$, I-67.

SPERRY, R. W. (1950). Neural basis of the spontaneous optokınetic response produced by visual neural inversion. Journal of Comparative \& Physiological Psychology, 43, 482-489.

Teghtsoonian, R., Teghtsoonian, M., \& Karlsson, J. G. (1981). The limits of perceived magnitude: Comparison among individuals and among perceptual continua. Acta Psychologica, 49, 83-94

WING, A. M. (1996). Anticipatory control of grip force in rapid arm movement. In A. M. Wing, P. Haggard, \& J. R. Flanagan (Eds.), Hand and brain: The neurophysiology and psychology of hand movements (pp. 301-324). London: Academic Press.

(Manuscript received July 21, 1998; revision accepted for publication October 21, 1998.) 